\title{
A Study of Clinico-Pathological Concordance in Leprosy Patients in the Post-Elimination Era
}

\author{
Sandeep $\mathbf{M}^{1}$, Shamanur Murugesh ${ }^{2}$ \\ ${ }^{1}$ Post-graduate, Department of Dermatology, Venereology and Leprosy, JJM Medical College, Davangere, Karnataka, India- 577004 \\ ${ }^{2}$ Professor and Head of department, Department of Dermatology, Venereology and Leprosy, JJM Medical College, Davangere, Karnataka, \\ India- 577004
}

\begin{abstract}
Histopathological correlation of skin biopsies in 89 leprosy patients was done with clinical diagnosis using Ridley Jopling classification. There was clinico-pathological agreement in $65.16 \%$ of cases. The correlation was highest in LL (75\%) followed by BL (70\%), BT (63.4\%), and TT (50\%).
\end{abstract}

Keywords: Histo-pathological correlation, leprosy, Ridley-Jopling classification

\section{Introduction}

Leprosy is a chronic, infectious disease caused by Mycobacterium leprae, infectious in some cases, and affecting the peripheral nervous system, the skin, and certain other tissues ${ }^{5}$

Leprosy presents in different clinico-pathological forms, depending on the immune status of the host. There are several classification systems in place for the clinical spectrum of leprosy and the most common used classification in clinical practice is the Ridley Jopling classification of leprosy.

The study of pathological changes in leprosy lesions has contributed to the understanding of the disease and clinicopathological correlative studies have provided insights into the disease, its varied manifestations and complications. Pathological examination helps to confirm a presumptive clinical diagnosis and also helps for exact typing. The study was undertaken to correlate different types of leprosy histopathologically and clinically.

\section{Materials and Methods}

\subsection{Study design: Material and Methods}

We did a retrospective analysis of 89 clinically suspected cases of leprosy, which were biopsied from June 2014 to May 2015 after obtaining approval from the ethical committee at our institution. Skin biopsies were taken from active lesions in all patients after obtaining informed consent and biopsies were stained by Hematoxylin \& Eosin stain. The clinical and histopathological diagnoses were correlated.

\section{Inclusion Criteria:}

All patients with different clinical spectrum of leprosy, were included in the study and graded as per the Ridley-Jopling classification into TT, BT, BB, BL and LL

\section{Exclusion Criteria:}

Patients already treated with anti-leprosy medications in any time earlier were excluded.
A detailed history regarding the age, sex, occupation, and residence, duration of the disease, age of onset, medical and family history was obtained. A thorough dermatological examination was made to note the extent, site and type of lesions. Clinical diagnosis was made using Ridley Jopling classification. Histopathologic examination of the haematoxylin and eosin stained slides was done by the dermatopathologists.

\section{Results}

A total of 89 patients were studied between June 2014 and May 2015. Out of the 89 patients, 68 were males (76.4\%) and 21 were females $(23.6 \%)$ [Figure 1].

Figure 1: Sex distribution of patients

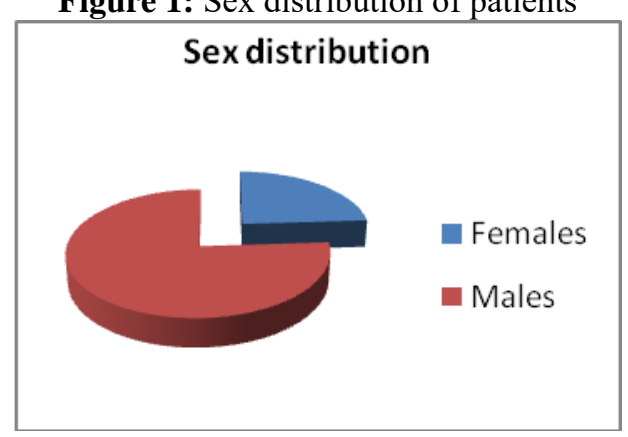

The age of the patients varied from 6 to 70 years with mean age of 38.5 years. Majority of the patients were in the age group $21-30$ years. Clinical diagnosis of the patients is as in Table 1.4 patients presented in reactions- One patient with Type 1 reaction and three patients with Type 2 reaction. The overall clinico-pathological correlation was seen in 58 cases. The maximum correlation was noted in LL patients $(75 \%)$ followed byBL (70\%), BT(63\%) and TT (50\%) 


\section{International Journal of Science and Research (IJSR) \\ ISSN (Online): 2319-7064}

Index Copernicus Value (2013): 6.14 | Impact Factor (2014): 5.611

Table 1: Clinical diagnosis of Hansen's disease in 89

patients

\begin{tabular}{|c|c|c|}
\hline Clinical diagnosis & Numbers & Percentage \\
\hline Tuberculoid leprosy & 2 & 2.25 \\
\hline Borderline tuberculoid & 47 & 52.8 \\
\hline Mid borderline & 0 & 0 \\
\hline Borderline lepromatous & 34 & 38.2 \\
\hline Lepromatous & 4 & 4.5 \\
\hline Pure Neuritic & 1 & 1.1 \\
\hline Histoid & 1 & 1.1 \\
\hline
\end{tabular}

\subsection{Results}

A disease like leprosy needs an appropriate classification because of its varied manifestations. Of the many classification systems described in literature, Ridley-Jopling classification is one of the well placed systems in clinical practice. Also called as immunological classification, Ridley Jopling classification is based on immunological, bacteriological and clinical features of leprosy. These include,

1) Tuberculoid leprosy (TT)

2) Borderline tuberculoid leprosy (BT)

3) Mid borderline leprosy (BB)

4) Borderline lepromatous leprosy (BL)

5) Lepromatous leprosy (LL)

In the present study, Ridley-Jopling classification was used to classify leprosy both clinically and histopathologically. Out of 89 cases, the diagnosis of 58 cases correlated clinically and histopathologically (55.03\%) [Figure 2].

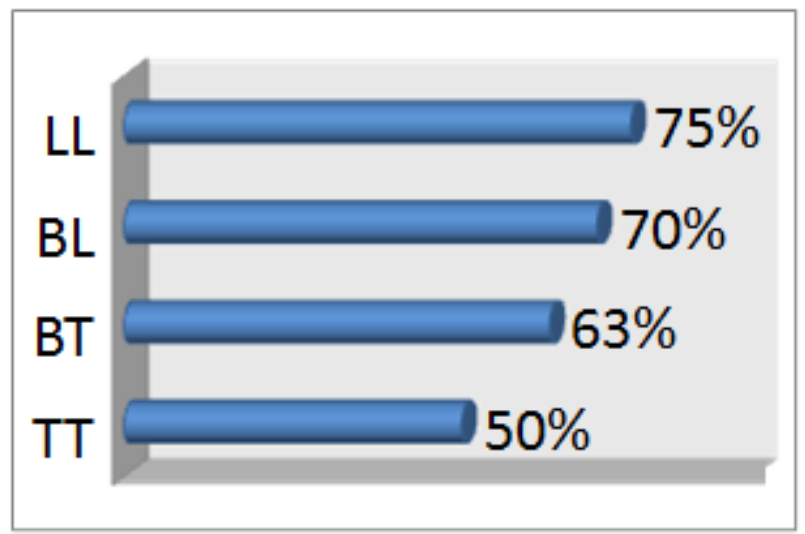

Comparative study of clinico $\neg$ pathological correlation by different workers is as in table 2 .

\begin{tabular}{|c|c|c|c|c|c|}
\hline $\begin{array}{c}\text { Type of } \\
\text { leprosy }\end{array}$ & $\begin{array}{c}\text { Jerath and } \\
\text { Desai, } \\
1982(1)\end{array}$ & $\begin{array}{c}\text { Nadakarni } \\
\text { and Rage, } \\
1982(3)\end{array}$ & $\begin{array}{c}\text { Bhatia et } \\
\text { al,1983 (2) }\end{array}$ & $\begin{array}{c}\text { Niranjana } \\
\text { moorthy et } \\
\text { al, 1999 (4) }\end{array}$ & $\begin{array}{c}\text { Present } \\
\text { study }\end{array}$ \\
\hline TT & 74.5 & 97.2 & 50.00 & 46.15 & 50.00 \\
\hline BT & 64.7 & 95.0 & 77.00 & 66.66 & 63.00 \\
\hline BB & 53.8 & 89.0 & 25.00 & 50.00 & 0 \\
\hline BL & 28.5 & 87.0 & 43.00 & 70.00 & 70.00 \\
\hline LL & 61.5 & 98.2 & 91.00 & 80.00 & 75.00 \\
\hline
\end{tabular}

The correlation was better at lepromatous pole (LL and BL) than the tuberculoid pole (TT and BT). Maximum disagreement between clinical and histopathological diagnosis was observed in midborderline cases of present study. Midborderline leprosy is immunologically the least stable and can present with clinical lesions of different morphologies in the same patient. It is therefore necessary to relate the histological features with the the particular morpholgical lesion subjected to biopsy. If this is done carefully, it may be possible to achieve a better correlation of clinical with the histological changes. (6)

The disparity between clinical and histological observations was anticipated because the parameters used for the histopathologic classification are well-defined, precise and also take into account the immunologic response of the tissue, while the clinical classification gives recognition only to the gross appearances of the lesions which is due to the underlying pathological change. Moreover, a sizable proportion of leprosy cases $(\mathrm{BT}+\mathrm{BB}+\mathrm{BL})$ are in a continuously changing immunological spectrum and histological classification gives a better indication for any recent shift of a case position in the spectrum. 2

There is no independent gold standard for diagnosis of leprosy. Taking any of the clinical signs, clinical types, histopathologicaI parameters or histopathological types as a gold standard is not ideal. The variation in different studies may be due to different criteria used to select the cases and difference in number of cases of each type. Various factors also influence the histopathological diagnosis such as differences in sample size, choosing the biopsy site, age of the lesion, immunological and treatment status of the patient at the time of biopsy. Clinical diagnosis of early leprosy lesions offer difficulties even to experienced dermatologists and leprologists. A definitive diagnosis may be possible by histopathological examination. The other important point to be considered is inter-observer variation, both clinically and histopathologically. As there can be some degree of overlap between different types of leprosy, both clinically and histopathologically, correlation of clinical and histopathological features along with bacteriological index appears to be more useful for accurate typing of leprosy than considering any one of the single parameters alone.(6)

\section{Conclusion}

With the clinical diagnosis of leprosy as per Ridley Jopling classification, skin biopsies were sent for histopathological examination for confirmation of diagnosis. Typing of leprosy is important in management, complications and prognosis of the patient. There can be some degree of overlap between different types of leprosy both clinically and histopathologically due to inter observer variation

\section{References}

[1] Jerath VP, Desai SR. Diversities in clinical and histopathological classification of leprosy. Lepr India 1982; 54:130.

[2] Bhatia AS, Katoch K, Narayanan RB, et al. Clinical and histopathological correlation in the classification of leprosy. Int J Lepr 1993; 61:433-438.

[3] Nadkarni NS, Rege VL. Significance of histopathological classification in leprosy. Indian J Lepr 1982; 71:325-332. 


\section{International Journal of Science and Research (IJSR) \\ ISSN (Online): 2319-7064}

Index Copernicus Value (2013): 6.14 | Impact Factor (2014): 5.611

[4] Moorthy B N, Kumar P, Chatura K R, Chandrasekhar H $\mathrm{R}$, Basavaraja P K. Histopathological correlation of skin biopsies in leprosy. Indian J Dermatol Venereol Leprol 2001;67:299-301

[5] Jopling WH, McDougall AC. Handbook of leprosy, 5th edition, Delhi, CBS Publishers and Distributors, 1996; 10-53.

[6] Sharma A, Kumar R, Goswami KC, Bardwaj S. ClinicoHistopathological Correlation in Leprosy . JK Science 2008; Vol. 10(3):120-123. 